\title{
Neonatal Care and the Issue of Disclosure of Information
}

\author{
George Gregory Buttigieg* \\ University of Malta, Europe
}

Received: January 02, 2018; Published: January 10, 2018

${ }^{*}$ Corresponding author: George Gregory Buttigieg, University of Malta, Europe

\section{Editorial}

There is little doubt that the field of Neonatology has, and is, undergoing vast clinical changes as underlying research in all its background sciencesprogresses in leaps and bounds. One has also to realise that this progress as in all medical disciplines is multi-dimensional, and far beyond the simple clinical end-point expression of progress in neonatal medicine, pharmacology and surgery. Among these dimensions, the medico-legal aspect, looms large and over the recent years, has loomed larger still.

Medico-legal neonatology itself comprises many subdivisions, although here, the topic, deals with parental disclosure of medical information. It is crucial to reflect on the potential implications of failing to disclose sufficient inormation about any proposed treatment to the parents. It is just as crucial to train new neonatologists to aasume this stance de rigeur. For it does not come instinctively. It is also somewhat demoralising to reflect on the potential legal comebacks to the young neonatologist, brimming with knowledge, enthusiasm and an irrepressible will to safe the vulnerable neonate. Yet, one painful and disturbing lesson taught by medico-legal medicine is that healers who are good, well informed, updated, capable and sincere in their efforts to heal, may still have to face Court to answer for medical negligence.

One way by which, such a neonatologist find himself facing a negligence claim is through insufficient or absent disclosure of information to the parents. I give one example based on the fact that in preterm infants, systemic postnatal corticosteroid therapy to prevent or treat chronic lung disease, though effective in improving lung function, may cause Cerebral Palsy. This is a delicate situation where the doctor may well feel that "doctor knows best". In truth doctor does know best but in 2017, this is not synonymous to the fact that "hence he can administer what he wants." The paternalistic attitude is no longer condoned by the Courts, in any aspect of medicine, if and when, a clinical situation reaches Court on a basis of alleged liability of medical negligence. Hence, in this situation, the neonatologist needs must explain to the parents why he needs to give steroids, what might happen if they are withheld, if alternatives exist, what is the known relationship to cerebral palsy.

The increasing Court emphasis is on patient autonomy in accepting or refuting treatment. To exert such autonomy, it is up to the doctor to furnish the necessary details, as applied to the situation at hand. In the case of the neonate, that the right of autonomy, falls on the parents, within very wide and strong limits. The patient's right to disclosure has been enormously strangthened by the UK High Court ruling in Montgomery v Lanarkshire Health Board, 2015. UKSC 11, where Bolam's Law with regard to disclosure was essentially demolished. Among the implications of this, is the fact that a doctor can no longer quote similar peer action in his defence. Now more than ever, the doctor must inform well his patient as to what he is proposing. This may not be easy, especially in the presence of limited ability to understand by the patient or limited ability to portray facts by the doctor and various degrees of either or both combined. Factors such as diminished intellect, limitations of hearing or vision, language barriers, to mention but a few, may compound a difficult situation into a herculean task.

My personal opinion is that the future will witness an increase in litigation as based on alleged failure of disclosure of information. I have on numerous occasions proposed that one aspect of medicolegal medicine is a platform for medical education. This is a case in point. Both under and post-gradiuate medical teaching need to inculcate a mind-set which vitalises and challenges the student's ability to verbalise, communicate and defend his decision making. This is not necessarily as simple as it sounds. It also demands an education in ego-control. A medical specialist, sub-specialist or super sub-specialist may not, understandably, take too kindly to an illiterate person defiant attitude in refusing treatment for a newborn.

I think one is unjustified in borrowing the $1^{\text {st }}$ Duke of Wellington's aphorism about publishing and being damned to suit the modern medico-legal dangers and warn one and all : Disclose or be damned! 
(c) (i) This work is licensed under Creative Commons Attribution 4.0 License

DOI: 10.32474/PAPN.2018.01.000102

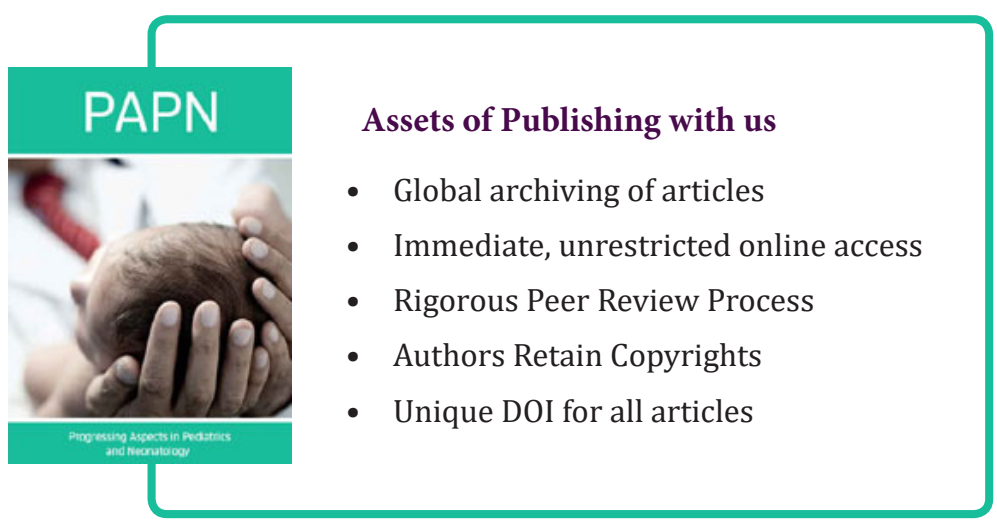

